www. revis ta d y o. com

\title{
Comparative Analysis of Firms' Participation in National and International Programmes to Support Innovation
}

Análisis comparativo de la participación de las empresas en programas nacionales e internacionales de apoyo a la innovación

\author{
Antonio Hidalgo ${ }^{1}$, José Molero², Inés Granda ${ }^{3}$, José Albors ${ }^{4}$ \\ 1'Dep. Ingeniería de Organización, Administración de Empresas y Estadística. Escuela Técnica Superior \\ de Ingenieros Industriales. Universidad Politécnica de Madrid \\ 2 Dep. Economía Industrial. Universidad Complutense de Madrid. \\ ${ }^{3}$ INNOPRO, Universidad Politécnica de Madrid y GRINEI, Universidad Complutense de Madrid. \\ ${ }^{4}$ Dep. Organización de Empresas. Universidad Politécnica de Valencia. \\ ahidalgo@etsii.upm.es, jmolero@icei.ucm.es, igranda@etsii.upm.es, jalbors@doe.upv.es
}

Fecha de recepción: 10-02-2014

Fecha de aceptación: 02-02-2015

\begin{abstract}
Innovation is a process that faces several market failure situations. For this reason and for being considered one of the main drivers of economic growth, a large number of governmental and supranational policies are designed to foster technological progress. Along with these policies, there is an increasing concern with their continuous evaluation aiming at providing valuable feedback for these program's adaptation and adequacy to the firm's needs. The paper develops an evaluation of the influence of innovation-focused programs in firm's innovation and economic performance by means of a comparative analysis of the results obtained by Spanish firms that have participated in R\&D national programmes and those achieved by Spanish firms participating in EUREKA international program. Findings show that the programmes were effective in achieving their objective of promoting technological innovation but, as regards the economic effects, the results were less conclusive since some differences were observed depending on the programme. The EUREKA companies displayed better behaviour, with positive differences in their returns on assets and labour productivity. The results also confirm the importance of designing more detailed and rigorous evaluation processes, taking into account the risk variable, in order to draw a more realistic picture of the impact of national and international programmes.
\end{abstract}

Keywords: Innovation, technology policy, technological cooperation, internationalisation, Eureka

Resumen: El objetivo de este artículo es contribuir al conocimiento del impacto que tiene en las empresas su participación en programas públicos de apoyo a la innovación tecnológica, introduciendo como importante novedad el análisis comparado de los resultados obtenidos por las empresas españolas que han participado en programas de I+D de ámbito nacional (proyectos empresariales de I+D gestionados por el CDTI) frente a las que lo han hecho en programas internacionales (programa EUREKA). Los resultados muestran que ambos programas son eficaces en el logro de su objetivo de promover la innovación tecnológica, pero, en cuanto a sus efectos económicos, los resultados son menos concluyentes.

Palabras clave: Innovación, Política tecnológica, cooperación tecnológica, internacionalización, eureka

\section{Introduction}

Since the seminal work of Arrow (1962), it is generally accepted that the market is unable to efficiently allocate the resources necessary for research and innovation activities because knowledge-related activities have characteristics commonly ascribed to public goods.
Thus, the absence of public intervention to compensate for this situation would lead to underinvestment in socially activities which are desirable to achieve technological progress (Martin and Scott, 2000; Hall, 2002; Bönte, 2004).

There has been a proliferation of policies designed to stimulate business research, development and innova- 
tion in all countries, irrespective of the political focus of their governments. However, this proliferation has not always been based on sufficient evidence that such policies may actually improve the behaviour and performance of companies in the area of innovation (Díez, 2001). In other words, market failures are a necessary but insufficient condition to justify the allocation of public funds to innovation support that may be used for other purposes; such allocation could only be justified if it is empirically confirmed that public programmes improve the innovation activities and thus the economic performance of firms (Hewitt-Dundas and Roper, 2010).

This suggests the importance of conducting rigorous evaluations of programmes designed to support technological innovation, especially if two characteristic features of innovation policies are considered. Firstly, the actual complexity of innovation itself makes the search for simple cause-effect relationships between the objectives of specific programmes and their outcomes increasingly redundant (Arnold, 2004): an example of the possible contradiction is that a percentage of the success of a given action may be due to its relatively unambitious goals (Zabala-Iturriagagoitia et al, 2008).

Secondly, the increasing variety and complexity of these policies complicates their evaluation due to the difficulty of designing appropriate analysis tools. This particularly affects international programs due to the difficulty involved in defining the contextual conditions that have to be taken into account and the behaviour of the project teams (Gilbert et al, 2004; Ebersberger et al, 2008). Although this is important, it is even more important in the case of economies which, like the Spanish economy, are characterized by a clear delay between efforts and the results of technological innovation (Molero, 2011; Eurostat, 2012).

In recent decades, international policies adopted to support technological innovation have introduced an even more complex element, since it is unclear whether such policies provide improved or even different levels of efficiency than do national policies. In this respect, attention must be drawn to the growing European dimension of important technological innovation policy initiatives, in particular the launch in 1985 of the EUREKA Programme, which is oriented more directly towards market activities than alternative initiatives in other European policies, notably the R\&D Framework Programmes which have a pre-defined thematic structure.

The aim of this article is therefore to contribute to our knowledge of the impact on firms of their participation in public programmes to support technological innovation, introducing one important novelty, a comparative analysis of the results obtained by Spanish firms that have participated in national programmes (R\&D projects managed by the Centre for Industrial Technological Development -CDTI) and those achieved by Spanish firms participating in international programmes (the EUREKA programme). Knowledge of the advantages and disadvantages of both experiences - R\&D support at national level and individual programs versus collaborative collaboration in international environments - can help improve the design and implementation of different tools for public intervention in the field of innovation.

\section{Background and Framework}

After analysing whether it is appropriate to develop policies to help improve the allocation of public resources for technological innovation, research conducted on this topic has focused primarily on promoting public interventions that take into account the wide variety of forms of innovation, the wide range of factors involved and the importance of interaction between companies and the international environment in innovation processes (Nelson, 2007; Pianta and Varona, 2009).. In general, there has been a shift from actions aimed principally at boosting traditionally conceived research and development towards actions that strive to enhance the visibility of the different potential forms of innovation, emphasizing interaction in what has become known as the "knowledge triangle" and encompassing all the above in a systematic vision of how innovation works, which requires new approaches in the design of policies to promote innovation (Ebersberger et al, 2008; Dodgson et al, 2011).

In terms of innovation policy, special attention must be drawn to three areas that have been studied extensively, the results of which frame this research paper: the first and more general problem, involves the relationship between technological innovation and economy; the second is the study of the overall impact these policies may also have on innovation activities; and the third relates to the evaluation of programmes or policies, in terms of both their performance and impact on firms participating in such programmes.

In relation to the first area, numerous studies have been carried out to gauge the returns from R\&D activities to the economy, while others have focused more on the relationships between innovation and productivity (Crepon et al, 1998; Wieser, 2005; Castellacci, 2008). In general terms, R\&D or innovation activities, clearly yield positive returns, but the magnitude of the effect varies and is not always significant (Bartelsman and Doms, 2000; Hall et al, 2011; Hall, 2011). However, the 
relationship is influenced by different factors: some authors suggest that investment in knowledge may be a necessary but insufficient condition to produce results, and specifically highlight the existence of "venture capital" (Audretsch and Keilbach, 2008) or, more generally, the relationships between technological and social or institutional capacities (Fagerber and Srcholec, 2008). Some researchers have also considered the diminishing returns on R\&D spending, which might be responsible for the phenomenon known as the "Nordic paradox": the apparent contradiction whereby countries which invest strongly in R\&D seem only to achieve medium levels of growth in productivity (Lang, 2009).

The second area, which is more directly related to the subject of this paper, involves neoclassical studies that examine the relationship between the policies and innovation activities of firms, based on a market's failure to allocate resources to innovation (Dodgson et al, 2011). Numerous studies have focused on the impact of incentives for private R\&D and resources allocated by companies, but these studies have not examined any specific policy or programme in depth. The aim of these studies was to determine whether an additional positive impact was achieved whereby such incentives prompted companies to allocate more resources, or whether this had some type of substitution effect, i.e. companies offset the allocation of more public resources with lower contributions of their own capital. Although this type of additionality effect has been most commonly studied, other types of additionality can be identified, for example the obtainment of more patents or more new products and processes (the results of innovation) or the achievement of better economic results by companies.

In terms of incentives to encourage firms to engage in R\&D activities, the two most commonly analysed incentives are direct aid and tax incentives. In the case of direct aid many studies have been published which coincide in finding that there is a positive additionality of resources that favours firms who allocate resources to R\&D (Arvanitis et al, 2002; Almus and Czarnitzki, 2003; Guellec and Van Pottelsberghe, 2003; Duguet, 2004; Görg and Strobl, 2007; Aerts and Schmidt, 2008; González and Pazo, 2010), although the magnitude of the effect is open to debate and sometimes the effect is actually the substitution of private resources by public resources. Abundant research has also been conducted on the impact tax incentives have on the R\&D activities of firms and the findings are similar: tax incentives have a positive influence on the R\&D activity of firms, in terms of either the decision to start such activity or to step up existing efforts (David et al, 2000; Wallsten, 2000; Hall and Van Reenen, 2000; Marra, 2004, 2006). There are some discrepancies in results in terms of the type and magnitude of the effects studied, but in the case of Spain, the existing literature is relatively consistent (Buson et al, 2010; González and Pazo, 2010).

The third area of interest is the study of the evaluation of specific policies or programmes designed to support technological innovation. This evaluation becomes more necessary as it recognizes the "trial and error" nature of many policies that need feedback from evaluations in order to refine their approaches and instruments (Metcalfe and Georghiu, 1997). In spite of this, research in this area is hardly encouraging (Kette et al, 2000); hence, further evaluations are required in order to acquire objective information on the results of technological innovation policies and obtain feedback on policy design, the analysis of results and the redesigning of these policies, taking into account on-going institutional changes (Georghiou, 1997; Nelson, 2007). However, a distinction must be made between studies that focus on analysing the rationality of programmes or their terms of governance and execution (Cimolli et al, 2006) from others, such as those examined here, which focus on measuring the specific results of firms that have participated in such programmes.

\section{EUREKA Programme}

EUREKA was founded in 1985 to challenge the increasing migration of R\&D and industrial innovation to Asian and North-American countries. Its aim is to promote international, market-oriented research and innovation through the support to small and medium-sized enterprises, large industry, universities and research institutes. Through EUREKA, these organisations are introducing new products, processes and services to market, helping make Europe economically strong and socially sound. Financing is variable and decisions about supporting participants depend solely on each country.

EUREKA currently consists of 38 member countries with a wide European geographical spread. After 25 years, 1.300 projects have been completed, with a total value of over $€ 14$ billion. Two-thirds of the participants are firms and $40 \%$ are small and medium enterprises. The EUREKA mechanism, with its flexibility and lack of bureaucracy, closely matches the requirements of European industry (Georghiou, 1998).

EUREKA carries out its own evaluation system through periodic reviews. In the period 1992-1993 Eureka had its first major evaluation, involving teams from 14 countries working together and carrying out a survey of all the participants (Georghiou and Roessner, 2000). According to Luukkonen (2002), this evaluation influenced evaluation traditions in Europe. However, as well as its 
internal evaluations, EUREKA has been the focus of several analyses:

- Fölster (1995) hypothesizes that given that EURE$\mathrm{KA}$ projects require cooperation but do not require result-sharing agreements, the likelihood of cooperation is lower.

- Barañano (1995) suggests that Spanish EUREKA participants see the improvement of the organization's public image as one of the most important features of the programme.

- Georghiou (2001) points out that EUREKA began with major projects but there was then a decline as a result of its divergence with national innovation policies.

- Marín and Siotis (2008) suggest that EUREKA serves the purpose for which it was designed, namely to correct the market failures associated with the generation of economically valuable knowledge.

- Bayona-Sáez and García-Marco (2010) demonstrate that participation in a EUREKA project has a positive effect on a firm's performance in both the manufacturing and non-manufacturing sectors, which is in accordance with results from Benfratello and Sembenelli (2002) which also highlight an increase in labour productivity and price-cost margins for participants. They also find that there is a one year lag between project completion and performance improvements.

But it is important to take into account the fact that even though the results presented are mainly positive, continuous assessments and even different research might not only identify weaknesses of the programme, but also provide the information necessary for adaptations and changes in the initiative's characteristics.

\section{CDTI Projects}

The CDTI (Centre for Industrial Technological Development) is a public entity that promotes research, development and technological innovation Spain. It strives to enhance the competitiveness of Spanish companies, improving their technological level by evaluating and funding research, development and technological innovation projects.

The main features of these R\&D projects are that they seek to develop new industrial processes or products, are applied research projects and are based on the development of new technologies in companies.
Few studies have attempted to evaluate the effectiveness of R\&D projects financed by the CDTI. However, some have focused on this objective, notably the study by Molero and Buesa (1997), who presented the results of a survey on technological innovation in 1354 Spanish companies participating in these types of projects in the period 1984- 1995. The study analysed data about the international activity of these companies, their competitive position, the resources they allocated to innovation and the organisation of the technology creation process, their results and how these were achieved. Molero and Buesa (1998), based on the same survey, analysed effects of the company projects financed by CDTI and attempted to measure the importance of financial support for Spanish industrial companies. Busom (2000) used data about companies that received CDTI aid in 1988 and compared its impact with data from other innovative companies that did not receive such support. The author reported that public support generally boosted private initiatives and small firms were better able to participate in programmes. Lastly, Huergo and Trenado (2008) analysed the key factors that determine the likelihood of companies applying for soft loans from the CDTI to finance their R\&D projects and this agency's decisions and selection of beneficiaries of such loans. These factors focus on the company's ability to carry out research (budget, technical development capacity, degree of innovation of the project and the potential for exploiting and marketing results).

\section{Methodology and Variables}

The analysis was carried out using two databases provided by the CDTI containing information on all the companies in both groups: one containing the data of Spanish firms participating in the EUREKA programme in 2000-2006 (EUREKA companies), and another containing the data of Spanish firms participating in CDTI projects in the same period (CDTI companies). 264 firms participated in EUREKA programme and 2,888 companies in CDTI projects.

In terms of size, an initial descriptive analysis revealed that most companies were small and medium-sized enterprises and its percentage was higher among the CDTI companies (85\%) than the EUREKA firms (73\%). In terms of sectoral distribution, industrial companies accounted for the largest percentage in both groups and were particularly high among CDTI companies $(63 \%)$. The percentage of service sector companies is larger in the EUREKA (42\%) than in the CDTI group $(33 \%)$, and in both groups primary sector companies accounted for a very small percentage of the total (Figure 1). 

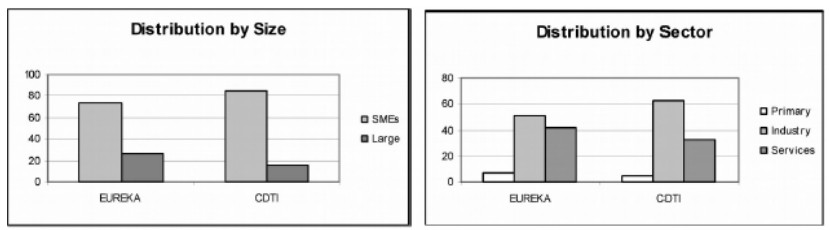

Figure 1. Sample distribution

The variables used in the analysis were grouped into two specific areas: economic variables and variables relating to the technological innovation capacity of the firm. The economic variables were total assets, sales, number of employees and added value. The technological variables were total R\&D expenditure, spending on patent applications and spending on computer software. The analysis period was 1998-2008, three years before and three years after the companies participated in the corresponding projects.

The data for carrying out the analyses was obtained from the SABI database (Iberian Balance Sheets Analysis System). Economic and technological information was extracted from this database for 235 of the 264 EUREKA companies and 2,650 of the 2,888 companies that participated in CDTI projects. The firms that participated in both programmes were not taking into account.

This information was used to develop five indicators (two economic and three technological) for these companies:

- Economic indicators: return on assets (ROA), defined as earnings before taxes divided by total assets, and labour productivity (LP), measured as added value for employment.

- Technological indicators: weight of R\&D on added value (R\&D/AV), weight of patent applications on added value (PAT/AV) and software on added value (Al/AV). The latter indicator brought another perspective to the impact analysis, namely the impact of participation in aid programmes on the incorporation of information and communication technologies (ICT) in companies. This aspect is particularly important for Spanish firms given the relative delay of the Spanish economy in the use of ICT in the production and management of firms.

In order to compare the results of firms before and after their participation in the corresponding programme, two statistical tests were performed for related samples: a parametric test (t in differences), and a non-parametric test (Wilcoxon test), comparing the situation of companies before the completion of the projects (up to three years before) with the results obtained after their completion (up to three years later).

Parametric tests assume a normal distribution and if this assumption is not rejected, these tests are deemed to be more robust than non-parametric tests (Hair et al, 2010). Given the large number of observations for each variable, it was possible to accept this assumption (central limit theorem). However, a non-parametric test was also conducted and, although less robust, it was not based on any specific distribution assumption. The results for the EUREKA and CDTI companies in both tests yielded very similar conclusions.

The analysis allowed to identify the indicators in which significant differences were observed in the behaviour of companies after their participation in the different programmes. In addition to the analysis of companies as a whole, other comparisons were made differentiating by size and sector of activity.

\section{Main Results}

\section{Descriptive Analysis}

An initial descriptive analysis of the variables in the year of project completion revealed that the EUREKA companies displayed higher average returns on assets (ROA) and expenditure on patent applications and software than the CDTI firms. However, these companies presented higher labour productivity, while R\&D effort was very similar in both groups (Table 1). 


\begin{tabular}{|c|c|c|c|c|c|c|}
\hline & & ROA & PL & R\&D/AV & PAT/AV & $\mathrm{Al} / \mathrm{AV}$ \\
\hline \multirow[t]{2}{*}{ EUREKA } & Mean & 4.73 & 4.73 & 32.05 & 6.80 & 7.30 \\
\hline & $\begin{array}{c}\text { Stand a r d } \\
\text { dev. }\end{array}$ & 14.46 & 3.16 & 39.60 & 26.19 & 17.82 \\
\hline \multirow[t]{2}{*}{ CDTI } & Mean & 1.64 & 5.68 & 32.53 & 2.08 & 3.68 \\
\hline & $\begin{array}{c}\text { S t a n d a r d } \\
\text { dev. }\end{array}$ & 15.54 & 7.43 & 27.15 & 6.36 & 4.33 \\
\hline
\end{tabular}

The analysis by company size showed that EUREKA companies (both large firms and SMEs) achieved higher returns on assets (ROA) than CDTI companies, and these returns were particularly high in large EUREKA companies (with a value of 9.36). The same trend was observed in the expenditure on patent applications and software variables, irrespective of company size. In contrast, labour productivity was greater in CDTI companies, while the impact of R\&D expenditure depended on company size; the impact was greater in large EUREKA companies and CDTI SMEs, the highest value being observed in smaller companies (Table 2).

\begin{tabular}{|c|c|c|c|c|c|c|c|}
\hline & & & ROA & PL & R\&D/AV & PAT/AV & $\mathrm{Al} / \mathrm{AV}$ \\
\hline \multirow{4}{*}{$\begin{array}{c}\text { Large } \\
\text { Companies }\end{array}$} & \multirow[t]{2}{*}{ EUREKA } & Mean & 9.36 & 4.74 & 26.49 & 3.51 & 4.06 \\
\hline & & $\begin{array}{c}\text { Standard } \\
\text { dev. }\end{array}$ & 12.52 & 2.93 & 20.18 & 6.91 & 4.31 \\
\hline & \multirow[t]{2}{*}{ CDTI } & Mean & 2.33 & 5.91 & 15.44 & 0.98 & 3.20 \\
\hline & & $\begin{array}{c}\text { Standard } \\
\text { dev. }\end{array}$ & 12.21 & 11.28 & 19.63 & 1.55 & 3.62 \\
\hline \multirow[t]{4}{*}{ SMEs } & \multirow[t]{2}{*}{ EUREKA } & Mean & 3.08 & 4.73 & 35.07 & 8.39 & 8.81 \\
\hline & & $\begin{array}{c}\text { Standard } \\
\text { dev. }\end{array}$ & 14.78 & 3.25 & 47.06 & 31.61 & 21.29 \\
\hline & \multirow[t]{2}{*}{ CDTI } & Mean & 1.47 & 5.63 & 37.30 & 2.31 & 3.83 \\
\hline & & $\begin{array}{c}\text { Standard } \\
\text { dev. }\end{array}$ & 16.25 & 6.16 & 43.33 & 6.96 & 4.54 \\
\hline
\end{tabular}

Finally, the analysis by sector of activity revealed that the main differences between the two groups appeared in primary sector companies in relation to returns on assets (ROA) and software expenditure, with EUREKA companies presenting higher values. CDTI companies presented much higher values in terms of R\&D effort.
In the industrial sector, the main difference observed was the high ROA of EUREKA companies.

Finally, EUREKA service sector companies presented much higher average expenditure on software than CDTI firms (Table 3 ). 
Table 3. Descriptive analysis (firms by sector)

\begin{tabular}{|c|c|c|c|c|c|c|c|}
\hline & & & ROA & $\mathrm{PL}$ & R\&D/AV & PAT/AV & $\mathrm{Al} / \mathrm{AV}$ \\
\hline \multirow{4}{*}{$\begin{array}{c}\text { Primary } \\
\text { sector }\end{array}$} & \multirow[t]{2}{*}{ EUREKA } & Mean & 6.02 & 4.48 & 1.74 & 1.73 & 7.12 \\
\hline & & $\begin{array}{c}\text { Standard } \\
\text { dev. }\end{array}$ & 7.11 & 4.03 & 2.06 & 3.40 & 9.10 \\
\hline & \multirow[t]{2}{*}{ CDTI } & Mean & 1.53 & 5.22 & 15.25 & 1.03 & 1.06 \\
\hline & & $\begin{array}{c}\text { Standard } \\
\text { dev. }\end{array}$ & 1.11 & 4.33 & 23.25 & 0.90 & 0.65 \\
\hline \multirow{4}{*}{$\begin{array}{l}\text { Industrial } \\
\text { sector }\end{array}$} & \multirow[t]{2}{*}{ EUREKA } & Mean & 7.34 & 5.35 & 31.41 & 3.58 & 3.63 \\
\hline & & $\begin{array}{c}\text { Standard } \\
\text { dev. }\end{array}$ & 12.04 & 2.73 & 26.02 & 6.15 & 3.23 \\
\hline & \multirow[t]{2}{*}{ CDTI } & Mean & 1.14 & 5.81 & 32.63 & 2.22 & 3.78 \\
\hline & & $\begin{array}{c}\text { Standard } \\
\text { dev. }\end{array}$ & 17.12 & 8.72 & 137.67 & 6.99 & 4.52 \\
\hline \multirow{4}{*}{$\begin{array}{c}\text { Service } \\
\text { sector }\end{array}$} & \multirow[t]{2}{*}{ EUREKA } & Mean & 1.12 & 4.12 & 39.09 & 1.33 & 9.51 \\
\hline & & $\begin{array}{c}\text { Standard } \\
\text { dev. }\end{array}$ & 7.53 & 3.40 & 61.97 & 1.83 & 9.23 \\
\hline & \multirow[t]{2}{*}{ CDTI } & Mean & 2.40 & 5.37 & 39.79 & 1.78 & 3.47 \\
\hline & & $\begin{array}{c}\text { Standard } \\
\text { dev. }\end{array}$ & 11.98 & 4.37 & 51.01 & 2.81 & 3.65 \\
\hline
\end{tabular}

\section{Statistical Analysis}

As explained, the aim of the statistical analysis is to determine whether significant differences in economic and technological aspects were observed in the companies after the completion of their projects. The time elapsing until the impacts were noticeable was also analysed comparing the existing situation three years before the end of the project with that after three years of the project completion (it was expected that if the programmes had an impact on business performance, these results would not be immediate). Tables 4 to 9 show the results statistically significant at the $10 \%$ level in both parametric and non-parametric tests.

Tables 4 and 5 present the results of the difference-in-means test on the technological and economic indicators for all firms participating in both programmes. The binomial indicates the time when a significant difference was observed, where i was the project completion year, and the negative or positive numbers the years before or after the completion of the project. For example, the binomial $(i-1, i+1)$ would indicate the observation of a significant difference between the values of the analysed variable one year before and one year after the completion of the project.

It was generally observed that after the completion of the projects, the differences in technological results were more significant in the CDTI companies than in the EUREKA companies (Table 4). In terms of R\&D effort, the effects were observed in both programmes in the year of completion of the project, but sooner in EUREKA companies (significant difference within two years ago) than in CDTI companies, where the impact was observed within three years. As regards the other technological variables, in patent applications significant differences were only observed in CDTI companies and the effect on patents was not observed until two years after completion of the project, which is consistent with the time required to develop and publish patents. Significant differences were observed regarding the impact on software in the year of completion of the project in CDTI firms. In other words, the most 
immediate effect was observed in relation to the introduction of ICT as a sign of modernisation, while results in other technological areas were obtained much later.

Table 4. Tests on mean differences for technological indicators (total firms)

Parametric Test ( $\mathrm{t}$ in differences for related samples)

\begin{tabular}{|c|c|c|c|}
\cline { 3 - 4 } \multicolumn{2}{c|}{} & EUREKA & CDTI \\
\hline \multirow{2}{*}{ R\&D/AV } & Year of impact & $(\mathrm{i}-2, \mathrm{i})$ & $(\mathrm{i}-3, \mathrm{i})$ \\
& $\mathrm{t}$ Student & 2.148 & 2.123 \\
& Sign & 0.041 & 0.042 \\
\hline \multirow{3}{*}{ PAT/AV } & Year of impact & - & $(\mathrm{i}-\mathrm{I}, \mathrm{i}+2)$ \\
& $\mathrm{t}$ Student & - & 1.781 \\
& Sign & - & 0.079 \\
\hline \multirow{3}{*}{ AI/AV } & & - & \\
& Year of impact & - & $(\mathrm{i}-2, \mathrm{i})$ \\
& $\mathrm{t}$ Student & - & 2.569 \\
& Sign & - & 0.011 \\
\hline
\end{tabular}

Non-parametric Test (Wilcox test)

\begin{tabular}{|c|c|c|c|}
\cline { 3 - 4 } \multicolumn{2}{c|}{} & EUREKA & CDTI \\
\hline \multirow{2}{*}{ R\&D/AV } & Year of impact & $(\mathrm{i}-2, \mathrm{i})$ & $(\mathrm{i}-3, \mathrm{i})$ \\
& $\mathrm{z}$ & 2.931 & 2.582 \\
& Sign & 0.041 & 0.010 \\
\hline \multirow{3}{*}{ PAT/AV } & Year of impact & - & - \\
& $\mathrm{z}$ & - & - \\
& Sign & - & - \\
\hline \multirow{3}{*}{ Al/AV } & & & \\
& Year of impact & - & $(\mathrm{i}-\mathrm{-I}, \mathrm{i})$ \\
& $\mathrm{z}$ & - & 2.743 \\
& Sign & - & 0.006 \\
\hline
\end{tabular}

The analysis of the economic variables (Table 5) showed that productivity diminish significantly at the end of the project in CDTI companies, while in EUREKA companies a significant and positive difference was observed one year after completion of the project. This result is coherent with the findings of Benfratello and Sembenelli (2002), who also reported a positive association between participation in the EURE$\mathrm{KA}$ programme and labour productivity in a sample of 750 European manufacturing companies in the period 1992-1996. Meanwhile, significant differences were observed in returns on assets (ROA) in CDTI companies after completion of the project, which is consistent with the findings reported by Bayona and García
(2010) for a sample of 866 European companies in the period 1994-2003, although the positive influence on ROA was observed sooner (one year after the completion of the project).

Table 5. Tests on mean differences for economic indicators (total firms)

Parametric Test ( $\mathrm{t}$ in differences for related samples)

\begin{tabular}{|c|c|c|c|}
\hline \multicolumn{2}{|c|}{} & EUREKA & CDTI \\
\hline \multirow{3}{*}{ ROA } & Year of impact & - & $(\mathrm{i}, \mathrm{i}+3)$ \\
& $\mathrm{t}$ Student & - & 5.334 \\
& Sign & - & 0.000 \\
\hline \multirow{3}{*}{$\mathrm{PL}$} & & & \\
& Year of impact & $(\mathrm{i}-\mathrm{I}, \mathrm{i}+1)$ & $(\mathrm{i}-\mathrm{I}, \mathrm{i})$ \\
& $\mathrm{t}$ Student & 1.951 & -2.195 \\
& Sign & 0.053 & 0.028 \\
\hline
\end{tabular}

Non-parametric Test (Wilcox test)

\begin{tabular}{|c|c|c|c|}
\hline \multicolumn{2}{|c|}{} & EUREKA & CDTI \\
\hline \multirow{3}{*}{ ROA } & Year of impact & - & $(\mathrm{i}, \mathrm{i}+1)$ \\
& $\mathrm{z}$ & - & 4.135 \\
& Sign & - & 0.000 \\
\hline \multirow{3}{*}{ PL } & Year of impact & $(\mathrm{i}-\mathrm{I}, \mathrm{i}+1)$ & - \\
& z & 1.730 & - \\
& Sign & 0.084 & - \\
\hline
\end{tabular}

\section{Analysis by Company Size}

Given the expected variability in the effects of the participation of companies in these programmes due to the specific characteristics of individual firms, the same analysis was performed differentiating companies by size.

As shown in Table 6, the differences in R\&D effort were significant, irrespective of either company size or the group to which the firms belonged. This finding was consistent with one of the main objectives of both programmes: the promotion of technological innovation. In the case of large firms, a significant difference was observed in the year of completion of the project with respect to the situation two years earlier. However, the situation in small and medium-sized firms differed according to the type of programme: in companies participating in the EUREKA programme the effect was not observed until one year later and the difference was 
significant compared to the situation two years before the end of the project, whereas in companies participating in the CDTI projects a significant difference was observed in the year of completion of the programme.

Significant differences were observed in spending on the incorporation of ICT software in the year of project completion in large companies participating in both types of projects and in small and medium-sized enterprises participating in CDTI projects. The non-parametric test showed also a significant difference in Eureka small and mediumsize firms the year of project completion. Finally, no significant differences were observed in terms of spending on patent applications.

Table 6. Test on mean differences for technological indicators (firms by size)

\section{LARGE COMPANIES}

Parametric Test ( $\mathrm{t}$ in differences for related samples)

\begin{tabular}{|c|c|c|c|}
\hline \multicolumn{2}{|c|}{} & EUREKA & CDTI \\
\hline \multirow{3}{*}{ R\&D/AV } & Year of impact & $(\mathrm{i}-2, \mathrm{i})$ & $(\mathrm{i}, \mathrm{i}+\mathrm{I})$ \\
& $\mathrm{t}$ Student & 2.688 & 3.077 \\
& Sign & 0.028 & 0.008 \\
\hline \multirow{3}{*}{ PAT/AV } & Year of impact & - & - \\
& $\mathrm{t}$ Student & - & - \\
& Sign & - & - \\
\hline \multirow{3}{*}{ Al/AV } & Year of impact & $(\mathrm{i}-2, \mathrm{i})$ & $(\mathrm{i}-\mathrm{I}, \mathrm{i})$ \\
& $\mathrm{t}$ Student & 1.891 & 1.774 \\
& Sign & 0.078 & 0.086 \\
\hline
\end{tabular}

Non-parametric Test (Wilcox test)

\begin{tabular}{|c|c|c|c|}
\hline \multicolumn{2}{|c|}{} & EUREKA & CDTI \\
\hline \multirow{3}{*}{ R\&D/AV } & Year of impact & $(\mathrm{i}-2, \mathrm{i})$ & $(\mathrm{i}, \mathrm{i}+\mathrm{I})$ \\
& $\mathrm{z}$ & 2.073 & 2.947 \\
& Sign & 0.038 & 0.003 \\
\hline \multirow{3}{*}{ PAT/AV } & Year of impact & - & - \\
& $\mathrm{z}$ & - & - \\
& Sign & - & - \\
\hline \multirow{3}{*}{ AI/AV } & Year of impact & $(\mathrm{i}-2, \mathrm{i})$ & $(\mathrm{i}-\mathrm{I}, \mathrm{i})$ \\
& $\mathrm{z}$ & 2.327 & 2.001 \\
& Sign & 0.020 & 0.045 \\
\hline
\end{tabular}

SMEs

Parametric Test ( $\mathrm{t}$ in differences for related samples)

\begin{tabular}{|c|c|c|c|}
\hline \multicolumn{2}{|c|}{} & EUREKA & CDTI \\
\hline \hline \multirow{3}{*}{ R\&D/AV } & Year of impact & $(\mathrm{i}-2, \mathrm{i})$ & $(\mathrm{i}-3, \mathrm{i})$ \\
& $\mathrm{t}$ Student & 1.761 & 1.882 \\
& Sign & 0.096 & 0.070 \\
\hline \multirow{3}{*}{ PAT/AV } & Year of impact & - & - \\
& t Student & - & - \\
& Sign & - & - \\
\hline \multirow{3}{*}{ Al/AV } & Year of impact & - & $(\mathrm{i}-2, \mathrm{i})$ \\
& t Student & - & 2.146 \\
& Sign & - & 0.035 \\
\hline
\end{tabular}

Non-parametric Test (Wilcox test)

\begin{tabular}{|c||c|c|c|}
\hline \multicolumn{2}{|c|}{} & EUREKA & CDTI \\
\hline \multirow{3}{*}{ R\&D/AV } & Year of impact & $(\mathrm{i}-2, \mathrm{i})$ & $(\mathrm{i}-3, \mathrm{i})$ \\
& $\mathrm{z}$ & 2.286 & 2.252 \\
& Sign & 0.022 & 0.024 \\
\hline \multirow{3}{*}{ PAT/AV } & Year of impact & - & - \\
& $\mathrm{z}$ & - & - \\
& Sign & - & - \\
\hline \multirow{3}{*}{ Al/AV } & Year of impact & $(\mathrm{i}-2, \mathrm{i})$ & $(\mathrm{i}-2, \mathrm{i})$ \\
& $\mathrm{z}$ & 2.915 & 3.283 \\
& Sign & 0.004 & 0.001 \\
\hline
\end{tabular}

The analysis of the economic variables (Table 7) revealed significant differences in the eturns on assets (ROA) of large companies in both programmes. In the case of small and medium-sized firms, significant differences were only observed in the companies participating in CDTI projects after the completion of the project. The productivity variable had a positive impact in EUREKA and CDTI small and medium-sized companies but a negative effect in CDTI large companies, according to the parametric test. 
Table 7. Tests on mean differences for economic indicators (firms by size)

\section{LARGE COMPANIES}

Parametric Test ( $\mathrm{t}$ in differences for related samples)

\begin{tabular}{|c|c|c|c|}
\hline \multicolumn{2}{|c|}{} & EUREKA & CDTI \\
\hline \multirow{3}{*}{ ROA } & Year of impact & $(\mathrm{i}, \mathrm{i}+1)$ & $(\mathrm{i}-2, \mathrm{i})$ \\
& $\mathrm{t}$ Student & 2.047 & 3.232 \\
& Sign & 0.047 & 0.001 \\
\hline \multirow{3}{*}{$\mathrm{PL}$} & & - & \\
& Year of impact & - & -1.730 \\
& t Student & - & 0.085 \\
\hline
\end{tabular}

Non-parametric Test (Wilcox test)

\begin{tabular}{|c|c|c|c|}
\hline \multicolumn{2}{|c|}{} & EUREKA & CDTI \\
\hline \multirow{3}{*}{ ROA } & Year of impact & $(\mathrm{i}, \mathrm{i}+2)$ & $(\mathrm{i}-2, \mathrm{i})$ \\
& $\mathrm{z}$ & 2.475 & 4.41 \\
& Sign & 0.013 & 0.000 \\
\hline \multirow{3}{*}{ PL } & & - & \\
& Year of impact & - & $(\mathrm{i}-1, \mathrm{i})$ \\
& z & - & 1.741 \\
& Sign & & 0.082 \\
\hline
\end{tabular}

SMEs

Parametric Test ( $\mathrm{t}$ in differences for related samples)

\begin{tabular}{|c|c|c|c|}
\hline \multicolumn{2}{|c|}{} & EUREKA & CDTI \\
\hline \multirow{3}{*}{ ROA } & Year of impact & - & $(\mathrm{i}, \mathrm{i}+3)$ \\
& t Student & - & 4.600 \\
& Sign & - & 0.001 \\
\hline \multirow{3}{*}{$\mathrm{PL}$} & Year of impact & $(\mathrm{i}-1, \mathrm{i}+1)$ & $(\mathrm{i}-1, \mathrm{i})$ \\
& t Student & 2.124 & 0.303 \\
& Sign & 0.036 & 0.032 \\
\hline
\end{tabular}

Non-parametric Test (Wilcox test)

\begin{tabular}{|c|c|c|c|}
\hline \multicolumn{2}{|c|}{} & EUREKA & CDTI \\
\hline \multirow{3}{*}{ ROA } & Year of impact & - & $(\mathrm{i}, \mathrm{i}+1)$ \\
& $\mathrm{z}$ & - & 3.311 \\
& Sign & - & 0.001 \\
\hline \multirow{3}{*}{$\mathrm{PL}$} & Year of impact & $(\mathrm{i}-1, \mathrm{i}+1)$ & $(\mathrm{i}-1, \mathrm{i})$ \\
& z & 1.862 & 3.160 \\
& Sign & 0.063 & 0.002 \\
\hline
\end{tabular}

\section{Analysis by Sector}

The analysis was also elaborated taking into account the three main economic sectors; a higher disaggregation was not possible because in many cases the number of Eureka firms was too small when the disaggregation is higher. The analysis differentiated by sector revealed no significant differences in terms of the technological impact in primary sector companies in either of the two groups (Table 8). In contrast, significant differences were observed in industrial companies belonging to both groups at the end of the project, in terms of both R\&D effort and software expenditure, compared with the situation in previous years. Significant differences in spending on patent applications were only observed in CDTI companies three years after completion of the project.

Finally, no impact was observed in service sector EUREKA companies after their participation in the programme. Significant differences were observed, however, in R\&D spending in CDTI companies two years after completion of the project compared with the efforts made during the years of project development. Significant differences in the incorporation of ICT through spending on software were observed in the year of completion of the project, thus confirming previous findings reported in the general study. 
Table 8. Tests on mean differences for technological indicators (firms by sector)

\section{Primary sector}

Parametric Test ( $\mathrm{t}$ in differences for related samples)

\begin{tabular}{|c|c|c|c|}
\hline \multicolumn{2}{|c|}{} & EUREKA & CDTI \\
\hline \multirow{3}{*}{ R\&D/AV } & Year of impact & - & - \\
& t Student & - & - \\
& Sign & - & - \\
\hline \multirow{2}{*}{ PAT/AV } & Year of impact & - & - \\
& t Student & - & - \\
& Sign & - & - \\
\hline \multirow{3}{*}{ AI/AV } & Year of impact & - & - \\
& t Student & - & - \\
& Sign & - & - \\
\hline
\end{tabular}

\begin{tabular}{|c|c|c|c|}
\hline \multicolumn{4}{|c|}{ Non-parametric Test (Wilcox test) } \\
\hline & & EUREKA & CDTI \\
\hline \multirow[t]{3}{*}{ R\&D/AV } & Year of impact & - & - \\
\hline & z & - & - \\
\hline & Sign & - & - \\
\hline \multirow[t]{3}{*}{ PAT/AV } & Year of impact & - & - \\
\hline & z & - & - \\
\hline & Sign & - & - \\
\hline \multirow[t]{3}{*}{$\mathrm{Al} / \mathrm{AV}$} & Year of impact & - & - \\
\hline & z & - & - \\
\hline & Sign & - & - \\
\hline
\end{tabular}

\section{Industrial sector}

Parametric Test ( $\mathrm{t}$ in differences for related samples)

\begin{tabular}{|c|c|c|c|}
\hline \multicolumn{2}{|c|}{} & EUREKA & CDTI \\
\hline \multirow{3}{*}{ R\&D/AV } & Year of impact & $(\mathrm{i}-2, \mathrm{i})$ & $(\mathrm{i}-3, \mathrm{i})$ \\
& $\mathrm{t}$ Student & 3.52 & 2.102 \\
& Sign & 0.003 & 0.045 \\
\hline \multirow{3}{*}{ PAT/AV } & Year of impact & - & \\
& t Student & - & $(\mathrm{i}, \mathrm{i}+3)$ \\
& Sign & - & 1.946 \\
& & & 0.057 \\
\hline \multirow{3}{*}{ Al/AV } & Year of impact & $(\mathrm{i}-2, \mathrm{i})$ & $(\mathrm{i}-2, \mathrm{i})$ \\
& $\mathrm{t}$ Student & 2.459 & 2.114 \\
& Sign & 0.02 & 0.037 \\
\hline
\end{tabular}

\begin{tabular}{|c|c|c|c|}
\hline \multicolumn{4}{|c|}{ Non-parametric Test (Wilcox test) } \\
\hline \multirow{2}{*}{ R\&D/AV } & EUREKA & CDTI \\
& Year of impact & $(\mathrm{i}-2, \mathrm{i})$ & $(\mathrm{i}-3, \mathrm{i})$ \\
& $\mathrm{z}$ & 2.864 & 2.649 \\
& Sign & 0.004 & 0.008 \\
\hline \multirow{3}{*}{ PAT/AV } & Year of impact & - & $(\mathrm{i}, \mathrm{i}+3)$ \\
& $\mathrm{z}$ & - & 3.137 \\
& Sign & - & 0.002 \\
\hline \multirow{3}{*}{ AI/AV } & Year of impact & $(\mathrm{i}-2, \mathrm{i})$ & $(\mathrm{i}-2, \mathrm{i})$ \\
& $\mathrm{z}$ & 2.234 & 3.543 \\
& Sign & 0.025 & 0 \\
\hline
\end{tabular}

\section{Service sector}

Parametric Test ( $\mathrm{t}$ in differences for related samples)

\begin{tabular}{|c|c|c|c|}
\hline \multicolumn{2}{|c|}{} & EUREKA & CDTI \\
\hline \multirow{2}{*}{ R\&D/AV } & Year of impact & - & $(\mathrm{i}-1, \mathrm{i}+2)$ \\
& $\mathrm{t}$ Student & - & 2.336 \\
& Sign & - & 0.052 \\
\hline \multirow{3}{*}{ PAT/AV } & Year of impact & - & - \\
& t Student & - & - \\
& Sign & - & - \\
\hline \multirow{3}{*}{ AI/AV } & Year of impact & - & $(\mathrm{i}-2, \mathrm{i})$ \\
& $\mathrm{t}$ Student & - & 2.238 \\
& Sign & - & 0.037 \\
\hline
\end{tabular}

Non-parametric Test (Wilcox test)

\begin{tabular}{|c|c|c|c|}
\hline \multicolumn{2}{|c|}{} & EUREKA & CDTI \\
\hline \multirow{2}{*}{ R\&D/AV } & Year of impact & - & $(\mathrm{i}-1, \mathrm{i}+2)$ \\
& $\mathrm{z}$ & - & 2.761 \\
& Sign & - & 0.006 \\
\hline \multirow{3}{*}{ PAT/AV } & Year of impact & - & - \\
& z & - & - \\
& Sign & - & - \\
\hline \multirow{2}{*}{ AI/AV } & Year of impact & $(\mathrm{i}-2, \mathrm{i})$ & $(\mathrm{i}-2, \mathrm{i})$ \\
& $\mathrm{z}$ & 2.101 & 3.615 \\
& Sign & 0.036 & 0 \\
\hline
\end{tabular}

In terms of economic results (Table 9), significant differences in the returns on assets (ROA) were observed sooner in the EUREKA companies than in the CDTI companies in all three sectors. In terms of labour productivity, no impact was observed in primary sector 
firms in either group, while EUREKA companies operating in the industrial and service sectors significantly increased their productivity, in contrast to the CDTI companies whose productivity declined, according to the parametric test.

Table 9. Tests on mean differences for economic indicators (firms by sector)

\section{Primary sector}

Parametric Test ( $\mathrm{t}$ in differences for related samples)

\begin{tabular}{|c|c|c|c|}
\hline \multicolumn{2}{|c|}{} & EUREKA & CDTI \\
\hline \multirow{3}{*}{ ROA } & Year of impact & $(\mathrm{i}-1, \mathrm{i}+1)$ & $(\mathrm{i}, \mathrm{i}+3)$ \\
& $\mathrm{t}$ Student & 2.002 & 2.091 \\
& Sign & 0.067 & 0.042 \\
\hline \multirow{3}{*}{$\mathrm{PL}$} & & - & - \\
& Year of impact & - & - \\
& t Student & - & - \\
\hline
\end{tabular}

\begin{tabular}{|c|c|c|c|}
\hline \multicolumn{4}{|c|}{ Non-parametric Test (Wilcox test) } \\
\hline & & EUREKA & CDTI \\
\hline ROA & $\begin{array}{c}\text { Year of impact } \\
z \\
\text { Sign }\end{array}$ & $\begin{array}{c}(\mathrm{i}-2, \mathrm{i}+1) \\
2.310 \\
0.021\end{array}$ & $\begin{array}{l}(\mathrm{i}, \mathrm{i}+3) \\
1.877 \\
0.060\end{array}$ \\
\hline PL & $\begin{array}{c}\text { Year of impact } \\
z \\
\text { Sign }\end{array}$ & $\begin{array}{l}- \\
- \\
-\end{array}$ & $\begin{array}{l}- \\
- \\
-\end{array}$ \\
\hline
\end{tabular}

\section{Industrial sector}

Parametric Test ( $\mathrm{t}$ in differences for related samples)

\begin{tabular}{|c|c|c|c|}
\hline \multicolumn{2}{|c|}{} & EUREKA & CDTI \\
\hline \multirow{2}{*}{ ROA } & Year of impact & $(\mathrm{i}+1, \mathrm{i})$ & $(\mathrm{i}, \mathrm{i}+3)$ \\
& $\mathrm{t}$ Student & 1.824 & 4.148 \\
& Sign & 0.003 & 0.000 \\
\hline \multirow{3}{*}{$\mathrm{PL}$} & & & \\
& Year of impact & $(\mathrm{i}-1, \mathrm{i})$ & $(\mathrm{i}-2, \mathrm{i}+1)$ \\
& t Student & 2.000 & -3.790 \\
& Sign & 0.072 & 0.000 \\
\hline
\end{tabular}

Non-parametric Test (Wilcox test)

\begin{tabular}{|c|c|c|c|}
\hline \multicolumn{2}{|c|}{} & EUREKA & CDTI \\
\hline \multirow{3}{*}{ ROA } & Year of impact & $(\mathrm{i}, \mathrm{i}+1)$ & $(\mathrm{i}, \mathrm{i}+3)$ \\
& $\mathrm{z}$ & 2.485 & 5.206 \\
& Sign & 0.013 & 0.000 \\
\hline \multirow{3}{*}{$\mathrm{PL}$} & Year of impact & $(\mathrm{i}, \mathrm{i}+2)$ & $(\mathrm{i}-2, \mathrm{i}+1)$ \\
& z & 1.7130 .087 & 3.981 \\
& Sign & & 0.000 \\
\hline
\end{tabular}

\section{Service sector}

Parametric Test ( $\mathrm{t}$ in differences for related samples)

\begin{tabular}{|c|c|c|c|}
\hline \multicolumn{2}{|c|}{} & EUREKA & CDTI \\
\hline \multirow{3}{*}{ ROA } & Year of impact & $(i, i+2)$ & $(i, i+3)$ \\
& t Student & 2.262 & 3.206 \\
& Sign & 0.027 & 0.001 \\
\hline \multirow{3}{*}{ PL } & & & \\
& Year of impact & $(i-2, i+2)$ & $(i, i+1)$ \\
& t Student & 2.223 & -2.305 \\
& Sign & 0.031 & 0.022 \\
\hline
\end{tabular}

\begin{tabular}{|c|c|c|c|}
\hline \multicolumn{4}{|c|}{ Non-parametric Test (Wilcox test) } \\
\hline & $\begin{array}{c}\text { E U R E - } \\
\text { KA }\end{array}$ & CDTI \\
\hline \multirow{2}{*}{ ROA } & Year of impact & $(\mathrm{i}, \mathrm{i}+2)$ & $(\mathrm{i}, \mathrm{i}+3)$ \\
& $\mathrm{z}$ & 2.289 & 4.559 \\
& Sign & 0.022 & 0.000 \\
\hline \multirow{3}{*}{$\mathrm{PL}$} & Year of impact & $(\mathrm{i}-2, \mathrm{i}+2)$ & $(\mathrm{i}, \mathrm{i}+1)$ \\
& $\mathrm{z}$ & 2.158 & 4.721 \\
& Sign & 0.031 & 0.000 \\
\hline
\end{tabular}

\section{Conclusions}

Technological policy evaluation is a process of utmost importance in any economic context that aims to foster economic growth through technological progress and innovation. This paper seeks to provide information and feedback of the influence of innovation-focused programs in firm's innovation and economic performance that allow the continuous improvement of any kind of initiative (private, governmental or even supranational).

The results shed light on the objectives sought by firms when applying for national (CDTI) or international (EUREKA) projects. While the former program offers com- 
panies financing support for shorter term R\&D projects the latter offers a framework for their internationalisation and participation in strategic projects, especially advantageous for smaller firms. Additionally, CDTI projects favour shorter decision making on project approval and therefore the results will be attained in a shorter term including the achievement of productivity gains (as pointed out by Busom, 2000, and Huergo and Trenado, 2008). On the other hand, EUREKA involves longer negotiations and decision making. Their results will be attained at longer term and will include enhanced returns on investments. This program facilitates participant firms' coexistence with international environments where industrial property protection is a standard project result and therefore the higher patent impact of this program. These results confirm previous research (Cimolli et al, 2006).

The statistical analysis allowed to compare the results obtained by the companies before and after their participation in the corresponding programme to promote technological innovation, using two types of variables: economic and technological. The technological results of companies tended to improve, as evidenced in particular by a clear increase in R\&D effort as a result of their participation in the programmes, although the impacts were observed sooner in the EUREKA companies than in the CDTI companies and mainly in industrial sector. The more intensive introduction of information technology through spending on software differed significantly in larger industrial companies participating in both types of projects. However, spending on patent applications only differed significantly in CDTI industrial companies in which impacts were observed three years after completion of the project. These results could be interpreted by the difference in project monitoring in both programs. While a CDTI project doesn't have continuous monitoring except two or three milestone reviews by CDTI officers, EUREKA partners meet in a continuous basis to discuss project progress and are subjected to the influence of their partner's achievements throughout the project duration.

As regards the economic effects, the results were less conclusive since some differences were observed depending on the programme. The EUREKA companies displayed better behaviour, with positive differences in their returns on assets when each sector was analysed separately, and labour productivity also increased in most companies. However, results in the CDTI companies were less clear because although differences in their returns on assets were positive three years after their participation in the programme, their labour productivity showed a clearly negative trend following the paradox proposed by Lang (2009). This could be interpreted as a synergic effect of the international partner- ships established within the project participants confirming previous findings by researchers (Bayona-Sáez and García-Marco, 2010; Benfratello and Sembenelli, 2002). Furthermore, it could be concluded that both programs fulfil the principles of the additionality school (Arvanitis et al, 2002; Guellec and Van Pottelsberghe, 2003; Duguet, 2004; Görg and Strobl, 2007; Aerts and Schmidt, 2008; González and Pazo, 2010).

Finally, as far as the differences in economic and technological results are concerned, findings are very promising although further effort is required. Here the type of project and its technological risk will play a relevant role as it has been pointed out by various authors (Georghiou, 1997; Klette et al, 2000; Nelson, 2007). Nevertheless, the results confirm the importance of designing more detailed and rigorous evaluation processes in order to draw a more realistic picture of the impact of national and international programmes for Spanish firms.

\section{References}

AERTS, K. and SCHMIDT, T. (2008). "Two for the price of one? Additionality effects of R\&D subsidies: a comparison between Flanders and Germany". Research Policy 37, no. 5: 806-822.

ALMUS, M. and CZARNITZKI, D. (2003). "The effects of public RandD subsidies on firms' innovation activities: The case of Eastern Germany". Journal of Business and Economic Statistics 21, no. 2: 226-236.

ARNOLD, E. (2004). "Evaluating research and innovation policy: a systems world needs systems evaluations". Research Evaluation 13, no. 1: 3-17.

ARROW, K. (1962). "The economic implications of learning by doing". The Review of Economic Studies 29, no. 3:155-173.

ARVANITIS, S.; HOLLENSTEIN, $\mathrm{H}$. and LENZ, S. (2002)."The effectiveness of government promotion of advances manufacturing technologies (ATM): An economic analysis based on Swiss micro data". Small Business Economics 19: 321-340.

AUDRETSCH, D.B. and KEILBACH, M. (2008). "Resolving the knowledge paradox: knowledge, spillover, entrepreneurship and economic growth". Research Policy 37, no. 10: 1697-1705.

BARAÑANO, A. 1995. The Spanish innovative firm and the ESPRIT, RACE and EUREKA programmes: an organizational approach. Technovation 15, no.6: 
339-350.

BARTELSMAN, E.J. and DOMS, M. (2000). "Understanding productivity: lessons from longitudinal microdata". Journal of Economic Literature 38, no. 3: 569-594.

BAYONA-SÁEZ, C. and GARCÍA-MARCO, T. (2010). "Assessing the effectiveness of the Eureka Program". Research Policy 39, no. 10: 1375-1386.

BENFRATELLO, L. and SEMBENELLI, A. (2002). "Research joint ventures and firm level performance". Research Policy 31: 493-507.

BÖNTE, W. (2004). "Spillovers from publicly financed business R\&D: some empirical evidence from Germany". Research Policy 33, no. 10: 1635-1655.

BUSOM, I. (2000). "An empirical evaluation of the effects of R\&D subsidies". Economics of Innovation and New Technology 9, no. 2: 111-148.

BUSOM, I., CORCHUELO, B. and MARTÍNEZ, E. (2010). "Efectividad de los incentivos públicos a la investigación e innovación empresarial". In Análisis sobre Ciencia e Innovación en España, ed. L. Cruz, J. Molas and L. Madrid: Fecyt.

CASTELLACCI, F. (2008). "Technological paradigms, regimes and trajectories: manufacturing and service industries in a new taxonomy of sectoral patterns of innovation". Research Policy 37: 978-994.

CIMOLI, M., DOSI, G., NELSON, R. R. and STIGLITZ, J. E. (2006). "Institutions and policies shaping industrial development: an introductory note". Lem Working paper series, 2006/2.

CREPON, B., DUGUET, E. and MAIRESSE, J. (1998). "Research, innovation and productivity: an econometric analysis at the firm level". Economics of Innovation and New Technology 7, no. 2: 115-158.

DAVID, P., HALL, B.H. AND TOOLE, A.A. (2000). "Is public R\&D a complement or substitute for private $\mathrm{R} \& \mathrm{D}$ ? A review of the Econometric Evidence". Research Policy 29, no. 2: 497-529.

DÍEZ, M.A. (2001). "The evaluation of regional innovation and cluster policies: towards a participatory approach". European Planning Studies 9, no. 7: 907-923.

DODGSON, M., HUGHES, A., FOSTER, J. and METCALFE, J.S. (2011). "Systems thinking, market fail- ure and the development of innovation policy: the case of Australia". Research Policy 40, no. 9: 11451156.

DUGUET, E. (2004). "Are R\&D subsidies a substitute or a complement to privately funded R\&D? Evidence from France using propensity score methods for non-experimental data". Revue d'Économie Politique 114, no. 2: 225-237.

EBERSBERGER, B; EDLER, J. and LO, V. (2008). "Improving policy understanding by means of secondary analyses of Policy Evaluation: A concept development". Research Evaluation 17, no. 3: 175-186.

EUROSTAT (2012): European Union Scoreboard 2011. Brussels.

FAGERBERG, J. and SRHOLEC, M. (2008). "National innovation systems, capabilities and economic development". Research Policy 37, no. 3: 1417- 1435.

FÖLSTER, S. (1995). "Do subsidies to cooperative R \& $D$ actually stimulate $R \& D$ investment and cooperation?". Research Policy 24, no. 4: 403-417.

GEORGHIOU, L. (1997). "Issues in the evaluation of innovation and technology policy". Proceedings of the Conference on Policy Evaluation in Innovation and Technology, June 25-27, in Paris, France.

GEORGHIOU, L. 1998. Global cooperation in research. Research Policy 27: 611-626.

GEORGHIOU, L. and ROESSNER, D. (2000). "Evaluating technology programs: tools and methods". Research Policy 29: 657-678.

GEORGHIOU, L. (2001). "Evolving frameworks for European collaboration in research and technology", Research Policy 30: 891-903.

GILBERT, B., AUDRETSCH, D.B. and McDougall, P. (2004). "The emergence of Entrepreneurship Policy". Small Business Economics 23: 313-323.

GÖRG, H. and STROBL, E. (2007). "The effect of R\&D subsidies on private R\&D”. Económica 74: 215-234.

GONZÁLEZ, X. and PAZO, C. (2010). "Subvenciones públicas a la I+D y esfuerzo tecnológico privado". In Análisis sobre Ciencia e Innovación en España, ed. L. Cruz, J. Molas and L. Sanz. Madrid: Fecyt..

GUELLEC, D. and POTTELSBERGHE DE LA POTTERIE, B. (2003). "From R\&D to Productivity Growth: 
Do The Institutional Setting and The Source of Funds of R\&D Matter?" IIR Working Paper 03-26, Institute of Innovation Research, Hitotsubashi University.

HAIR, J.F., BLACK, B., BABIN, B., ANDERSON, R.E. and TATHAM, R.L. (2010). Multivariate Data Analysis Pearson. New York.

HALL, B. (2002). "The Financing of research and development". Oxford Review of Economic Policy 18, no. 1: 35-51.

HALL, B.H. AND VAN REENEN, J. (2000). "How effective are fiscal incentives for R\&D? A review of the evidence". Research Policy 29, no. 3: 449-469.

HALL, B. (2011). "Innovation and productivity", UNU-MERIT Working Papers 028.

HEWITT-DUNDAS, N. and ROPER, S. (2010). "Output additionality of public support for innovation: evidence for Irish manufacturing plants". European Planning Studies 18, no. 1: 107-122.

HUERGO, E. and TRENADO. (2008). "Los determinantes de la solicitud y concesión de créditos blandos. La empresa española y el apoyo del CDTI a la I+D+i.". Documento de trabajo 06, Departamento de Estudios, CDTI.

KLETTE, T.J., MOEN, J. and GRILICHES, Z. (2000). "Do subsidies to commercial R\&D reduce market failures? Microeconometric evaluation studies". Research Policy 29, no. 4-5: 471-495.

LANG, G. (2009). "Measuring the returns of R\&D. An empirical study of the German manufacturing sector over 45 years". Research Policy 38, no.9: 14381445.

LUUKKONEN, T. (2002). "Research evaluation in Europe: state of the art". Research Evaluation 11, no. 2: 81-84.
MARÍN, P.L. and SIOTIS, G. (2008). "Public policies towards Research Joint Venture: Institutional design and participants' characteristics". Research Policy 37: 1057-1065.

METCALFE, S.J. and GEORGHIOU, L. (1997). "Equilibrium and Evolutionary Foundations of Technology Policy", CRIC Discussion Paper, no. 3. Centre for Research on Innovation and Competition, University of Manchester.

MOLERO, J. and BUESA, M. (1997). "La innovación tecnológica en la empresa española: resultados de la Encuesta IAIF-CDTI (1995)", IAIF. Documento de Trabajo no. 5.

MOLERO, J. and BUESA, M. (1998). "Industrial technology partnership in Spain", STI Review, OCDE. Paris.

MOLERO, J. (2001). Innovación Tecnológica y Competitividad en Europa. Madrid: Síntesis.

NELSON, R. R. (2007). "Building Effective "Innovation Systems" Versus Dealing with "Market Failures" as Ways of Thinking about Technology Policy". Manchester Business School Working Paper, no. 548.

PIANTA, M. and VARONA, A. (2009). "New ideas for innovation policies in Europe", ICEI Paper, № 11.

WALLSTEN, S. (2000). "The effect of government-industry R\&D programs on private R\&D: the case of the small business innovation research program". Rand Journal of Economics 31: 82-100.

WIESER, R. (2005). "Research and development productivity and spillovers: empirical evidence at the firm level". Journal of Economic Surveys 19, no. 4: 587-621.

ZABALA-ITURRIAGAGOITIA, J.M., JIMÉNEZ-SÁEZ, F. and CASTRO-MARTÍNEZ, E. (2008). "Evaluating European Regional Innovation Strategies". European Planning Studies 16, no. 8: 1145-1160. 